\title{
A palavra enraizada de Ana Paula Tavares
}

Rita Chaves*

* Professora da Área de Estudos Comparados de Literaturas de Língua Portuguesa da USP. 
As pouco mais de setenta crônicas que compõem o volume O sangue da buganvília ${ }^{1}$, editado em 1998 pelo Centro Cultural Português de Cabo Verde, foram em princípio escritas para serem lidas em programa da Rádio de Difusão Portuguesa, com emissão também para os países africanos de língua portuguesa. A vinculação dos textos ao meio de transmissão poderia levar-nos a pensar que Ana Paula Tavares, autora de poemas caracterizados pelo apuro da linguagem e a delicadeza do estilo, teria, afinal, cedido à pressão desses tempos mais afeitos à pressa e à exposição, marcas que se contrapõem ao reino dos valores qualitativos em que costumamos situar a literatura. Se os jornais já nos parecem tomados pelo espírito massificante, mais apto a trivializar as experiências do que a permitir a apreensão do pessoal e do único, o que esperar do rádio, em que a transmissão oral parece ( e tantas vezes se torna ) tão presa ao circunstancial?

São expectativas que, se alimentadas, começam por se desfazer já no primeiro parágrafo da primeira página da primeira crônica. "Língua materna", o texto de abertura da coletânea vem avisar-nos que não há ali concessão à trivialidade, à banalização. E a leitura das que Ihe sucedem vão confirmar que o caminho trilhado leva à outra direção: o trabalho da cronista define-se pelo esforço de recuperar as verdades e a beleza escondidas pelas neblinas enganosas do cotidiano que, longe de serem desfeitas, são, não raramente, reforçadas pelos chamados órgãos de informação. No livro de Ana Paula, a cada crônica, o leitor se certifica da dimensão da tarefa assumida pela escritora e percebe que pode efetivamente confiar nas palavras com que J oão Nuno Alçada compôs o seu prefácio, registrando a existência de 
"seres privilegiados que se debruçam sobre a vida para a explicar com a sabedoria poética dos provérbios e ditos antigos, com o conhecimento ancestral dos pequenos fenómenos, ou mistérios profundos que nos vêm desde a Criação do M undo."

Tendo publicado em 85 um pequeno livro de belos poemas, Ana Paula Tavares é daqueles casos em que a estréia revela a escrita madura de quem é mesmo do ramo. A força de sua criação em Ritos de passagem² motivou durante anos uma grande ansiedade dos leitores que aguardavam a nova fornada para confirmar a qualidade do trabalho inaugural. E m 1998, portanto 13 anos depois, quando todos esperávamos o segundo livro de poemas, sai esse volume a causar surpresa àqueles privados do privilégio de ouvir a leitura dos textos pelo rádio. O impacto, no entanto, é passageiro: a mudança - do poema para a prosa - que envolve o espaço de expressão de sua voz limita-se à transmutação do gênero, apenas; porque mantém-se a concepção da palavra abraçada desde o início.

Na redação dessas crônicas, cuja natureza é tocada pela brevidade do espaço a ser ocupado e pela fugacidade do instante a ser apreendido, estão preservadas algumas das peculiaridades que encontramos no exercício de sua poesia. E, dentre elas, destacamos o apreço pelo essencial, pelo sentido agudo, refratário ao barateamento das palavras, um dos males da vida mundana. Insurgindo-se contra a loquacidade fácil, como que a ratificar sua posição, a autora não se inibe e declara:

\section{[...] custa tanto a ouvir a palavra desperdiçada nas ocasiões festivas, usadas como enfeite na lapela nas ocasiões solenes, banalizada em discurso de ocasião, manifesto de boas e más intenções mais uma vez a adiar a vida. (p. 49 ).}

Constatamos que à volatilidade da transmissão não está ligada a superficialidade da mensagem, nesse caso ciosa do seu dever e seu direito de, em certa medida, transformar o meio.

O gosto pela essência, que a faz desviar-se do supérfluo, não limita o arco dos assuntos a serem tratados. A gama temática nesse conjunto de textos é ampliada, refletindo o espetáculo igualmente vário que é o mundo. M as o que salta à sensibilidade do leitor, mais que a variedade da pauta, é a argúcia do olhar da narradora, projetada numa narrativa capaz de conferir unidade a uma série em princípio descompromissada com a continuidade. A diversidade dos temas, portanto, não espelha a fragmentação do ponto de vista, todo ele recortado pela coerência que resulta dessa feliz combinação entre o conhecimento adquirido pela leitura e a aprendizagem assegurada pela experiência. Essa "sabedoria", mais próxima do próprio processo de aprendizagem do que de um repositório de conhecimentos, 
permite que a palavra transite por muitos universos, pois o mundo sobre o qual se debruça também ele é cenário de movimento, e no quadro a ser delineado tanto cabe a reflexão sobre a perda e a resistência de tantas utopias como a descrição do funge do almoço, tradição quase ritual nos sábados angolanos.

Ressalte-se, aliás, entre os textos a atenção que recebe o trabalho feminino, nas mais elementares e sofisticadas formas, apreendidas na imprescindibilidade de sua execução. São as oleiras "de mãos que parecem asas" ( p. 63 ), são as mais velhas que ao preparar o funge e outras iguarias dão provas de transportar "a secreta ciência dos sabores" ( p.50), são as lentas mulheres que "afastam o sono e iluminam a pouca noite que ainda resta, transformadas em recipientes de várias cores e percorrem as ruas da cidade velha pelos caminhos diários da demanda das fontes."( $p .52)$. E é também $M$ ary $K$ ingsley, a inglesa que, entre os nomes masculinos - Livingstone, Richard B urton, Henrique de Carvalho, e tantos mais - imprimiu a marca feminna às narrativas de viagens, um dos campos de interesse da cronista. Associada ao campo do trabalho, em ações mescladas de arte, empenho, coragem e sofrimento, a mulher tem assinalada a sua dignidade. Diluem-se os mitos vazios de um feminismo retórico ou de um tradicionalismo exotizante para dar lugar à visão de um grupo que intervém na sociedade em que está inserido. Dessa maneira, A na Paula não fala pelas mulheres de sua terra ou de outras, fala com elas, abre-Ihes o lugar que elas já ocupam. É essa uma das maneiras de denunciar uma das muitas injustiças dos tempos que não param de correr.

Avessa aos fundamentalismos, sabe resistir à tentação da idealizar a decantada fragilidade do sexo. Porque é preciso saber distinguir o trigo do joio e mesmo de outros cereais, não pode condescender quando a imagem feminina se deixa colar às artimanhas do logro. Em "A princesa e os meninos à volta da fogueira", uma das mais impressionantes crônicas do livro, desvela-se com lucidez o pacto da hipocrisia celebrado pela mídia. O contraponto entre a gravidade do drama vivido pelas crianças angolanas e o exercício sem pudor de uma bondade de ocasião faz emergir a face cruel de uma imagem emoldurada pelo brilho. A mercantilização da dor de quem não tem nada para vender revela até onde pode chegar o abuso dos civilizados. As cores e formas da devastação e o rosto da "princesa loura e boa" são elementos de uma equação que bem reflete o grau de desigualdade. A serviço de uma causa que não é a declarada, a princesa converte-se em vampiro:

A guerra, o abandono e a fome são o pano de fundo de seres que a terra mãe nem sempre adoptou como devia. Seres crescidos antes do tempo e que se desenvolvem a meio caminho entre uma improvável chegada ao mundo dos adultos e a imprevisível, porque assente numa longa combinação de imponderáveis, construção do dia que passa. 
O rosto mais visível da devastação e da guerra tem olhos de criança, tão grandes e espantados como os símbolos solares das pinturas rupestres mais antigas.

A sua trajectória fez-se em câmara lenta num filme de terror com uma duração igual e coincidente com as suas próprias vidas.

É preciso que descansem e possam lamber, em paz, as suas próprias feridas. M as a princesa loura e boa está atenta, espelho meu, e no seu belíssimo cesto de maçãs, transporta o veneno da exposição, a falta de pudor para falar das feridas dos outros, os seus actos de boa vontade encomendados.

Alimenta-se de sangue e nunca foi ao Huambo : rebenta minas no cinema, na televisão e na rádio. (p. 93 )

Engana-se, porém, quem pense que o texto investe contra a celebração individual da princesa eleita pela mídia como a portadora dos valores humanitários. A crítica é mais contundente e, ao denunciar a lógica da comunicação no mundo moderno, essas duas páginas abordam pontas ocultas do horror e da iniquidade ainda servidos aos desvalidos. Com base em signos como espelho, duendes, dragões, caçadores e todo um universo de magia, a narradora destaca a inviabilidade da própria fantasia quando as feridas da guerra são o pão de cada dia. A espoliação assim chega ao nível máximo e como compensação parece restar apenas a solidariedade de encomenda que mais serve a quem finge oferecer do que a quem precisaria receber. A harmonia do happy end dos contos de fada é manchada: não é gratuita a alusão ao cesto de maçãs que nas histórias infantis faz parte da bagagem das bruxas interessadas em derrotar as princesas. Na composição da figura da heroína, a ambiguidade é fonte de perturbação e contamina a generosidade, o desvelo, o despreendimento, todos os traços de um comportamento vendido como reserva de humanidade em tempos tão sombrios. Com fina sensibilidde, a inteligência da autora demonstra que o que parece uma exceção é, na realidade, a expressão desses tempos, pois, instrumentalizados, os bons sentimentos apenas realçam a intensidade da exclusão. A conclusão é capital : num mundo assim organizado, até mesmo a imemorial ligação entre a infância e o reino dos príncipes e princesas está quebrada.

Nessa era de extremos, como bem chamou Eric Hobsbawn, o célebre historiador inglês, é necessário construir novos instrumentos para compreensão das coisas. A lâmina da poesia tem sido uma ferramenta adequada para penetrar em câmaras fechadas, em cantos escuros, por isso a ela a cronista se apega e seus textos atestam que a opção pela prosa, e pela prosa curta, não postula uma ruptura com o lírico. Ao contrário, através dos textos, vamos percebendo que a intimidade com a poesia manifesta-se de modo vivo, uma comunhão materializada no inesperado das imagens, na busca do insólito para falar do desconcerto do mun- 
do. O gesto de escrever parece simultâneo ao ato de compreender as coisas em torno, a observação direta completando-se, sem inibição, na interlocução que procura estabelecer com outros artistas da palavra. E novamente a ausência de preconceito dá o tom. Muitos de muitas paragens são convocados e comparecem no texto, seja em forma de epígrafe, de citação, ou de objeto do olhar. G ente diversa, identificada com terras e origens numerosas. Do L eopold Senghor ao compositor brasileiro que se faz presente pelo verso curtinho “Oh, insensatez..." E o cortejo se completa com Sophia de M ello B reyner, André B rink, L uandino Vieira, M ia Couto, Ruy Duarte de Carvalho, Honorat Aguessy, Eduardo Lourenço, Virgínia Woolf, Georges Duby, Antônio Callado, Leite de Vasconcellos, David Mestre, Ungulani B a K a K hossa, Gabriel Mariano, B eatriz ... Historiadores, antrópologos, escritores, pessoas anônimas e celebridades, todos são convidados a integrar essa rede de estórias acolhidas nas crônicas.

Se o mundo da poesia é o campo onde, por excelência, sua pena circula, a linguagem é tratada com cuidado. As imagens são cultivadas, a escolha dos vocábulos recebe grande atenção, a crença na ilusória objetividade da função denotativa é abandonada, instituindo-se a capacidade de sugerir como critério de seleção dos termos. A aparente referencialidade que pensamos encontrar na prosa solta é pretexto para falar de coisas fundas que o dia-a-dia acaba por turvar. Sem prejuízo da inteligibilidade que convém ao texto para ser ouvido - em lugares nem sempre apropriados para o ato - a escrita refina-se no uso dos recursos que definem a força da economia poética: a adjetivação recusa o exagero, as metáforas fogem ao previsto, os nomes procuram reduzir o abismo entre eles e as coisas. O predomínio da coordenação, eixo predominante na língua oral, combina-se com o imprevisto das associações com que se recorta o desenho de cada cena apresentada. Entre a voz que narra e o mundo narrado não existe o distanciamento da épica convencional, e as palavras traduzem a contração expressando a porosidade de um narrador nítida e serenamente comprometido com o que declara.

Na composição, impõem-se as sugestões do espaço primordial. Sem cruzar as linhas de um nacionalismo militante, a cronista deixa nítida a geografia que marca o seu modo de ver o mundo. É, pois, essencialmente africana a paisagem que orienta os seus sentidos. Congo, Cabo Verde, Kinshasa, Guiné, Wiriamu, $K$ alahari e tantos outros topônimos despontam confirmando as marcas da origem. M as é principalmente A ngola que nos surge a cada passo: as serras da Huíla (sua província natal), as pedras da K ibala, o Huambo atingido pela guerra, o D ondo, o K iapossi, as ruas maltratadas de Luanda ... Seguindo talvez o exemplo de António Cadornega, sobre qual se detém num de seus textos, ela parece ter igualmente percebido que "a história não é imune à consistência dos lugares onde se passa e que, por sua vez, a perpassam". (p. 17 ) 
Com efeito, os lugares e suas marcas constituem uma das presenças relevantes em todo o livro. Sem se confundir com um diário, a coletânea incorpora traços dos livros de viagem, investindo na memória como uma via de conquista do que parece perdido. As incursões realizam-se, então, também na dimensão temporal, e a viagem se faz e se refaz, buscando alcançar o distante, no espaço e no tempo, sem ignorar a energia e a relevância do contemporâneo e do contíguo. Nas revisitas ao passado, desmancha-se a atmosfera nostálgica para que a recordação, colhida em jogo dinâmico, venha iluminar o presente, remarcar as linhas e as cores que delineiam a vida atual. A memória atua na organização do presente, o que já aconteceu funciona como um impulso no difícil exercício de compreender os fatos e seus ritmos.

Tão importante, a memória é ela própria um dos temas freqüentes entre as crônicas. Em pelo menos três delas, a discussão aparece ligada à questão dos museus e sua organização. Fala aqui também o cuidado da historiadora, sempre sensível às trapaças do tempo. A relação, todavia, não foi sempre de total adesão. E m "Achados e perdidos", a confissão está clara:

Durante muito tempo havia uma relação confusa de profundo mal-estar quando olhava aquelas máscaras alinhadas segundo critérios de tamanho e conveniências de feitio. Era um mal estar provocado com a dimensão funerária de tudo aquilo do qual me era tão difícil separar. Cemitérios de estátuas cegas mortas de gesto, de linguagem e de corpo.

Contra a reação, atuou a consciência de que essa história um pouco aprisionada, freqüentemente retida tão longe do contexto onde foi vida, tem seu dinamismo, guarda sua magia na existência de um "outro museu detrás das colecções expostas". Na recuperação do papel da instituição que permite "atravessar os espelhos da memória e a procurar identidades perdidas no chão dos antepassados onde vivemos"( p. 101), reflete-se, sob outro prisma, a capacidade de perscrutar o oculto dessas crônicas.

Delas pode-se dizer ainda que refletem uma extraordinária consciência do ato de escrever. A presença flagrante da metalinguagem projeta a atuação de uma inteligência que se dispensa de artificialismos e que assume, sem qualquer traço de arrogância, uma certa dimensão pedagógica que a literatura pode desempenhar. Nesse domínio, podemos incluir as citações de eruditos e populares, a capacidade de transitar por ordens culturais diferentes, recusando-se a hierarquizar os valores e ensinamentos que daí retira. À vontade, em atitude francamente favorável à circulação de idéias e verdades, permite-se associar Barthes aos mais velhos Cokue e Lunda, os teóricos da literatura francesa à Beatriz - a dona da 
panela de histórias ouvidas na infância. A disponibilidade para aprender e dividir a aprendizagem transforma-se num antídoto contra a descrença e, apesar de muitos apesares "nestes tempos da cólera perturbado e doente" (p. 139), parece possível e saudável escapar ao niilismo a que tanta coisa convida, especialmentea certeza de um (o seu ) continente a arder. N esse sentido, a prática metalingüística deixa de configurar um ato de fechamento, um modo de exprimir a autonomia do literário, como, segundo Alfredo $\mathrm{B}_{0} \mathrm{si}^{3}$, ocorre nas realizações da poesia assombrada pelo pessimismo. Ao refletir sobre o código de que se vale, a autora relativiza o conhecimento, questiona certezas, mas não subscreve essa espécie de tratado negativista das teorias pós-modernas. Talvez resíduo de uma restante utopia, revela-se o desejo de acreditar que o texto funciona para além de si mesmo. Levemente, em tom de rebeldia sutil, deixa escapar:

Felizmente a palavra dissidente ficou de fora, pronta a usar: exerce sobre nós a enorme sedução do fruto proibido, durante tanto tempo, do sabor a loengos selvagens: corta os lábios, fere a boca, mas cura a sede e apazigua a fome. Colocada lado a lado da responsabilidade que nos cabe na transformação deste mundo dos homens e das mulheres, sabe a pouco, mas como é bom usar! ( $p .91$ )

Identificadas com o presente, como é próprio do gênero e do veículo para o qual foram destinadas, as crônicas de Ana Paula propiciam formas de se estender a força do instante captado. O passado, visitado através da evocação, se associa ao futuro anunciado com jeito de vaticínios, o que faz com que o texto persiga a função desempenhada na tradição oral. Basta lembrarmos das lições de Walter B enjamin, para quem a ação do narrador tradicional residia no conhecimento acumulado pela força da experiência (1985). E co de uma realidade pautada pela transição, a palavra constrói-se revelando-se também um ato de fronteira, deslizando entre o campo e a cidade, e a autora reforça sua autoridade colhendo de positivo o que essas matrizes podem oferecer. $\mathrm{Na}$ cidade, a extração tem lugar nos livros e nos museus, essas catedrais de saber codificado pela escrita e pela pesquisa. No campo, a colheita se oferece no contato direto com os sábios que têm na memória (sempre ela) a fonte essencial. Com esses narradores fadados à extinção pela impessoalidade do universo dominado pela informação, Ana Paula insiste em aprender, seduzida pela capacidade de intercambiar experiências tão rarefeita na contemporaneidade.

Cabe observar que é bastante reduzido o espaço ocupado pela crônica na história da literatura em Angola. Povoada por grandes poetas e expressivos 
ficcionistas, seu repertório não reúne uma galeria significativa de cronistas, muito embora seja patente o grande interesse da produção de Ernesto Lara Filho, no passado, e hoje já se possa assinalar a atuação em alguns jornais, sobretudo portugueses, de escritores como Pepetela, Ruy Duarte de Carvalho e J osé Eduardo Agualusa. Mesmo as relações tão frutuosas com a literatura brasileira, em cujo repertório têm lugar destacado nomes que vão de Machado de Assis ao poetas Manuel B andeira e Carlos Drummond de Andrade, passando por verdadeiros cultores do gênero como Rubem Braga, Paulo Mendes Campos, Fernando Sabino, Otto L ara R esende, não tiveram forte repercussão nesse campo. Também por isso, merece muita atenção a atividade de A na Paula, que na opção por uma atmosfera peculiar, com base no uso de uma linguagem tingida por um certo aspecto solene, estabelece um caminho muito próprio. A comunicabilidade por ela pretendida passa ao largo, por exemplo, do clima de coloquialidade muito presente entre os brasileiros citados. A voz que se desata em cada texto parece bem mais próxima da família dos narradores da tradição oral, convicta do seu papel de matriz de ensinamentos, ainda que se permita confessar perplexidades impostas pela confusão ou pelo vazio da vida na sociedade balizada por valores quantitativos.

Diante de cada crônica, agora impressa nas páginas do livro, o leitor, atento, vai percebendo que os textos, de fato, se potencializam se lidos em voz alta, porque guardam na elaboração de seus argumentos uma densa ligação com a oralidade. U ma oralidade que não é de comício, como alguns dos poemas orientados para o contato com as massas, nem de salão, como aqueles adequados aos saraus românticos. As crônicas de Ana Paula Tavares remetem, suavemente, à roda da fogueira, lugar de aprendizagem e crescimento na tradição africana. Ao investir nessa evocação, a escritora não consegue recuperar, evidentemente, a inteireza de um passado irremediavelmente perdido (como, aliás, qualquer passado), mas consegue manter viva uma referência fundamental de seu patrimônio cultural. Delicadamente, sua proposta confirma a viabilidade do rádio como uma atualização do tambor tribal, expressão utilizada por M cluhan, o famoso teórico da comunicação, para quem “o rádio é uma extensão do sistema nervoso central, só igualada pela própria fala humana"4 . Da dimensão de aldeia comumente associada a esse veículo de comunicação que fique, contudo, afastada a velha idéia de massificação de verdades com que se ameaça qualquer franja de autonomia. N um mundo onde os meios são cada vez mais a mensagem, Ana Paula relativiza o caráter autoritário que pode ter a voz quando mediada pela tecnologia ao escolher a carga sugestiva da poesia como instrumento de revelação.

4 MCLUHAN, Marshall. Os meios de comunicação. São Paulo: Cultrix, s/d. p. 340. 
Assumindo o compromisso contra a fragmentação que vitima o homem, a autora reclama para a sua obra algumas das funções pouco prestigiadas no mundo mercantilizado do presente: a função de satisfazer a necessidade de fantasia que distingue os homens, a função educativa e a função de conhecimento do homem e do ser. Ou seja, nas palavras de Antonio Candido, a função humanizadora que é a "capacidade de confirmar a humanidade do homem"5, exprimindo-o e atuando em sua própria formação. A aposta na humanização no reino da mercadoria ajuda-nos a compreender, inclusive, a escolha da buganvília ${ }^{6}$ que dá título ao volume. Para a voz autorizada da cronista:

Assim as nossas raízes de ferreiros muito antigos vão resistindo ao vento e à tempestade destes últimos tempos que, mais que o vento ou a areia do deserto, nos experimenta os corpos e vai retorcendo as almas.

Por isso, às vezes tenho dúvidas e dificuldades quando a conversa tem que ver com buganvílias. É que estas coisas de parentesco são muito difíceis de conhecer bem e distinguir nas nossas terras.

De uma coisa estou certa, venha quem vier, mudem as estações, parem as chuvas, esterilizem o solo, somos cada vez mais como as buganvílias: a florir em sangue no meio da tempestade. (p. 35)

CANDIDO, Antonio. “A literatura e a formação do homem”. In: Remate de males. Campinas: Instituto de Estudos da Linguagem, 1999. 